\title{
Effects of Reaction Conditions on Hydrogen Production of Fe Complexes Catalyst in Photocatalysis System
}

\author{
Yuan YANG ${ }^{1, a}$, Da-Tian FU ${ }^{2, b}$ and Xiu-Lan CAI ${ }^{1, c, *}$ \\ 1 Guangdong Pharmaceutical University, Guangzhou, China \\ 2 Hainan Cancer Hospital, Haikou, China

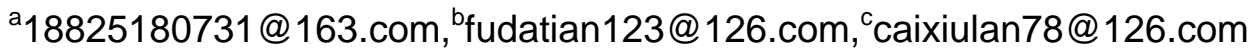 \\ ${ }^{*}$ Corresponding author
}

Keywords: Fe Complexes; Photocatalysis system; Reaction conditions

\begin{abstract}
Fe thiolate complexes $\mathrm{Fe}(\mathrm{bpy})(\mathrm{pyS})_{2}(\mathrm{M})$ were synthesized, the properties of complexes were characterized by $1 \mathrm{H}-\mathrm{NMR}$ and MS and the effects of reaction conditions on catalytic performance had been studied. The results of catalytic performance implied that when 5\% triethylamine was used as electron donor, $2.0 \mathrm{mM}$ fluoresce in was used as photosensitizer and the catalyst content was $2.5 \mu \mathrm{M}$, the hydrogen production of $\mathrm{M}$ reached89.6 $\mu \mathrm{mol} / \mathrm{h}$ after reacted for 15 hours.
\end{abstract}

\section{Introduction}

With the continuous emission of carbon dioxide, greenhouse effect are intensifying [1-3].In the past few years, noble metal complexes were used as catalysts in the hydrogen production, such asPt, $\mathrm{Pd}$ and $\mathrm{Rh}[4-9]$. It is economical that unsustainable noble metals could be replaced with some inexpensive metals. Recently, a kind of noble-metal-free catalyst [Co(dmgH $\left.)_{2}\right]$ had been reported for hydrogen production, the $\mathrm{H}_{2}$ evolution of 150 TON was observed[10].

In this paper, a new noble-metal-free complex $\mathrm{Fe}(\mathrm{bpy})(\mathrm{pyS})_{2}(\mathrm{M})$ was synthesized. The properties of complexes were characterized by ${ }^{1} \mathrm{H}-\mathrm{NMR}$ and MS, the effects of reaction conditions on catalytic performance had been studied.

\section{Experimental}

\subsection{Reagents and Instruments}

All reactions were carried out under $\mathrm{N}_{2}$ atmosphere with standard Schlenk techniques. Solvents

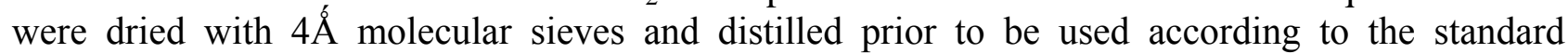
methods. Pyridine-2-thiol (pySH), 2,2'-bipyridine, 1,10-bpyanthroline hydrate, Cobalt nitrate hexahydrate, Manganese acetate tetrahydrate, sodium metal, fluorescein (Fl) and triethylamine (TEA) were purchased from Aldrich and used without further purification.

\subsection{Synthesis of $\mathrm{Fe}(\mathrm{bpy})(\mathrm{pyS})$}

$\mathrm{Fe}(\mathrm{bpy})(\mathrm{pyS})_{2}(\mathrm{M})$ was synthesized as Fig. 1 .The solution of 2,2'-bipyridine $(1.0 \mathrm{~g}, 6.4 \mathrm{mmol})$ in $10 \mathrm{~mL}$ of acetonitrile was added slowly to the solution containing $\mathrm{FeCl}_{3}\left(\mathrm{H}_{2} \mathrm{O}\right)_{6}(1.7 \mathrm{~g}, 6.4 \mathrm{mmol})$ in $80 \mathrm{~mL}$ of acetonitrile over $30 \mathrm{~min}$. The color of the above solution changed from light violet to dark violet. Then a solution containing pySH (1.42 g, $12.9 \mathrm{mmol})$ and TEA (2.2 mL, $16.0 \mathrm{mmol})$ in 30 $\mathrm{mL}$ of acetonitrile wasadded to above mixed solution slowly over $1 \mathrm{~h}$. The solution turned brown, and a brown precipitate formed after stirring for another $8 \mathrm{~h}$. The product (M1) was collected by suction filtration. The products were stored underatmosphere without protection from water and oxygen. 


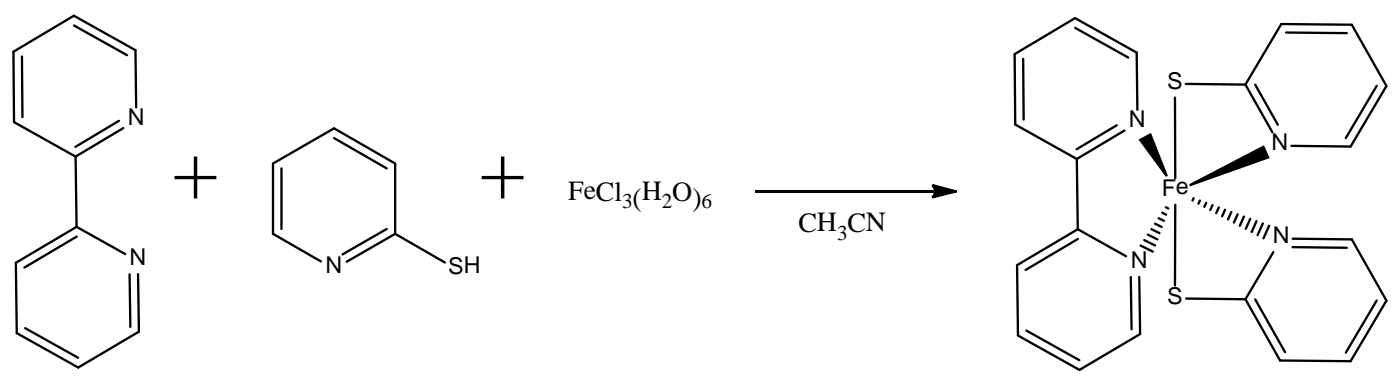

Fig. 1 The synthetic routes of $\mathrm{M}$

The yield of M1 was $1.7 \mathrm{~g}(74 \%) .{ }^{1} \mathrm{H}-\mathrm{NMR}\left(\mathrm{CDCl} 3,20{ }^{\circ} \mathrm{C}\right): \delta 8.7,8.18,7.48 \mathrm{ppm}$. ESI MS: $\mathrm{m} / \mathrm{z}$ 432.02 (expected), 432.02 (found). Elem. Anal. Calculated: C, 55.56; H, 3.73; N, 12.96; Found: C, 55.54; H, 3.76; N, 12.95 .

\section{$2.3{ }^{1} \mathrm{H}$-NMR Spectra}

${ }^{1} \mathrm{H}-\mathrm{NMR}$ spectra were collected on Varian INOVA 400NMR spectrometer.

\subsection{Mass Spectra}

Mass spectra were performed by electrospray ionization (ESI) onHP 1100 MSD instrument.

\subsection{Evaluation of Performance of Photocatalyst for Hydrogen Production}

The $0.04 \mathrm{mM}$ photocatalysts was placed in the mixed solution containingethanol/ $\mathrm{H}_{2} \mathrm{O}\left(1: 1_{\mathrm{v} / \mathrm{v}} 120\right.$ $\mathrm{mL}), 2.0 \mathrm{mM}$ Fland TEA (5\% v/v). The above mixed solution was place in an inner irradiation quartz cell $(250 \mathrm{~mL})$ and protected from light before use. The $\mathrm{pH}$ values of the solutions were measured withpH meter and adjusted to11.6 by adding $\mathrm{HCl}$ or $\mathrm{NaOH}$. The photocatalysis system were kept at $25^{\circ} \mathrm{C}$. The cell were irradiatedwith a $500 \mathrm{~W}$ Xe lamp and the produces were analyzed with an on-line TCD gas chromatograph (GC-9800).During the irradiation process, $0.5 \mathrm{~mL}$ methane was used as the internal standard gas, and the amount of hydrogen was calculated according to the amount of methane.

\section{Results and Discussion}

The results of previous studies indicated that the main influencing factors on performance of photocatalytic system for hydrogen production were electron donor, photosensitizer and catalyst content. In this paper, the effects of electron donor, photosensitizer and catalyst content on performance of catalyst $\mathrm{M}$ were investigated and the optimum conditions for hydrogen production were determined.

\subsection{The Effects of Electron Donor on the Performance of Catalyst $M$ for Hydrogen Production}

Catalyst M (0.04 mM) and fluorescein (2.0 mM) were added to the reactor, ethanol/water (V/V, 1:1) mixed solution was used as solvent of photocatalysis system. In the process of the reaction, $\mathrm{pH}$ value was 11.6, light intensity, stirring speed and temperature remained constant for $15 \mathrm{~h}$. The effects of two electron donor triethylamine and triethanolamine (two electron donor content was 5\%) oncatalytic performance were investigated and the experimental results were showed in Fig. 2. 


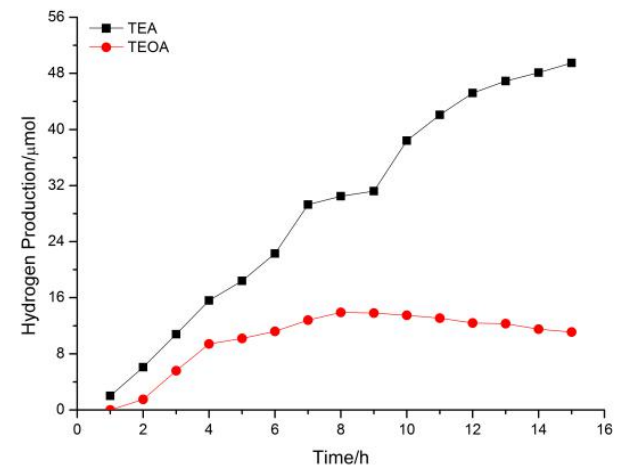

Fig. 2Effects of electron donor on the performance of catalyst $\mathrm{M}$ for hydrogen production

The results of Fig. 2 indicated that when electron donor was triethylamine, catalyst M presented the best catalytic performance and the hydrogen production reached $49.5 \mu \mathrm{mol}$ after reacted for 15 h. When triethanolamine was used as electron donor, the catalytic performance of $\mathrm{M}$ was significantly decreased and hydrogen production of $\mathrm{M}$ decreased after reacted for $12 \mathrm{~h}$, which indicated the deactivation of catalyst. Therefore, in this reaction system, triethylamine was the suitable electron donor.

\subsection{The Effects of Electron Donor Contents on the Performance of Catalyst $M$ for Hydrogen Production}

In addition, the effects of electron donor contents $(1.25 \%, 2.50 \%, 3.75 \%, 5 \%)$ on the catalytic performance of this reaction system were investigated respectively and the experimental results were showed in Fig. 3.

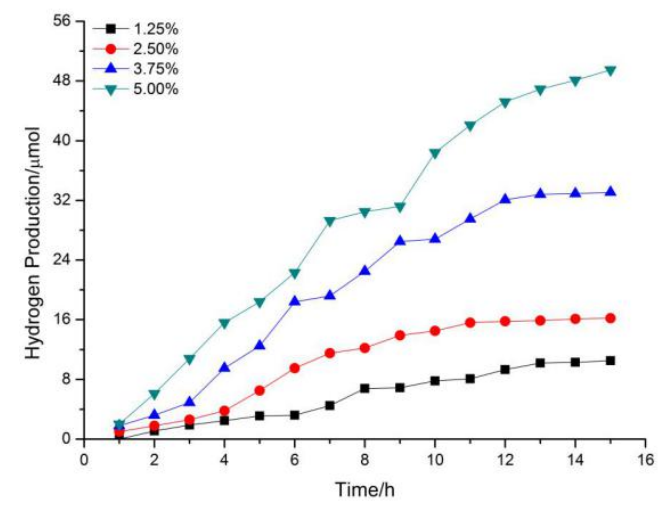

Fig. 3 Effects of electron donor contents on the performance of catalyst $\mathrm{M}$ for hydrogen production

Fig. 3 displayed that with the increasing of triethylamine contents from $1.25 \%$ to $5 \%$, the amounts of hydrogen production were increased gradually. When the triethylamine content was 5\%, catalyst $M$ showed the best catalytic performance. When the triethylamine content decreased to $1.25 \%$, the amount of hydrogen production was reduced to $8.9 \mu \mathrm{mol}$ after reacted for $15 \mathrm{~h}$. Therefore, the suitable triethylamine content was $5 \%$.

\subsection{The Effects of Photosensitizer on the Performance of Catalyst $M$ for Hydrogen Production}

The effects of photosensitizer (fluoresce in, eosin B and rose red impurity oxygen anthraquinone) on performance of catalyst $\mathrm{M}$ were investigated and the experimental results were showed in Fig. 4. 


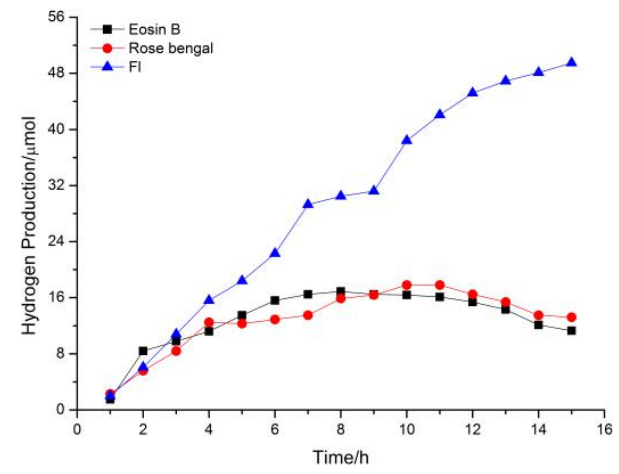

Fig. 4 Effects of photosensitizer on the performance of catalyst $M$ for hydrogen production

Fig. 4 presented that when fluoresce in was used as photosensitizers, hydrogen production reached the highest. But when the photosensitizer was eosin B or rose red, hydrogen production decreased obviously and when the reaction time was $11 \mathrm{~h}$, the hydrogen production of catalyst decreased which indicated the deactivation of catalyst. Therefore, in this photocatalytic system, fluoresce in was the suitable photosensitizer.

\subsection{The Effects of Photosensitizer Contents on the Performance of Catalyst $M$ for Hydrogen Production}

On the basis of above, the contents of photosensitizer fluoresce in $(0.25 \mathrm{mM}, 0.50 \mathrm{mM}, 1.0 \mathrm{mM}, 2.0$ $\mathrm{mM}$ and $2.50 \mathrm{mM}$ ) were investigated and optimized. The effects of photosensitizer contents on photocatalytic performance of catalyst were studied and the experimental results were showed in Fig. 5.

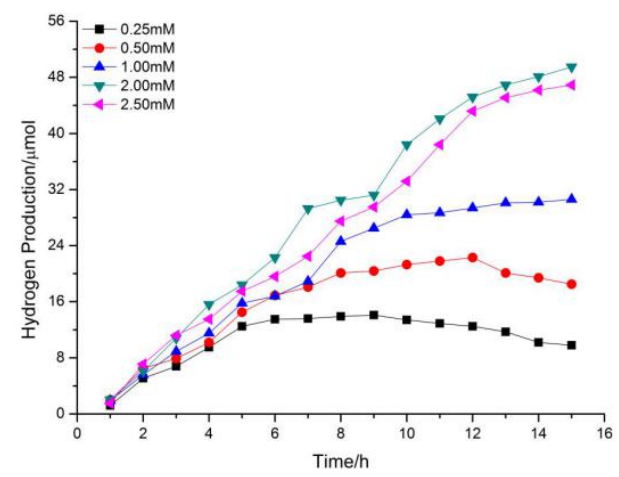

Fig. 5 Effects of photosensitizer contents on the performance of catalyst $\mathrm{M}$ for hydrogen production

Fig. 5 showed that with the gradual increasing of fluoresce in contents in this system, the amount of hydrogen production increased accordingly first and then decreased. When the content of fluoresce in was $2.0 \mathrm{mM}$, the hydrogen production reached the highest. After reacted for $15 \mathrm{~h}$, hydrogen production of catalyst $\mathrm{M}$ was $49.5 \mu \mathrm{mol}$. The above results determined that the optimal content of photosensitizer fluoresce in was $2.0 \mathrm{mM}$.

\subsection{The Effects of Catalyst Contents on the Performance of Catalyst $M$ for Hydrogen Production}

The effects of catalyst contents $(2.5 \mu \mathrm{M}, 5.0 \mu \mathrm{M}, 10.0 \mu \mathrm{M}, 20.0 \mu \mathrm{M}$ and $40.0 \mu \mathrm{M})$ on the photocatalytic hydrogen production were studied and the experimental results were showed in 
Fig.6.

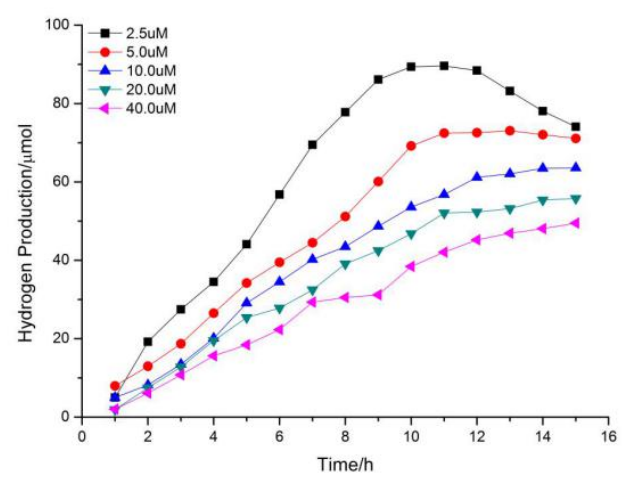

Fig. 6 Effects of catalyst contents on the performance of catalyst $\mathrm{M}$ for hydrogen production

The results of Fig. 6 indicated that with the reduction of catalyst contents, hydrogen production increased gradually. When the content of catalyst $\mathrm{M}$ was $40.0 \mu \mathrm{M}$, hydrogen production reached $49.5 \mu \mathrm{mol}$ after reacted for $15 \mathrm{~h}$. When the content of catalyst $\mathrm{M}$ was decreased to $2.5 \mu \mathrm{M}$, hydrogen production reached $89.6 \mu \mathrm{mol}$. Therefore, the he optimal content of catalyst was $2.5 \mu \mathrm{M}$.

\section{Conclusions}

Thiolate complexes Fe(bpy)(pyS)2 (M) had been synthesized and the performances of complexes $\mathrm{M}$ were studied. The results indicated Febalt thiolate complexes $\mathrm{M}$ was active for light-driven hydrogen production in aqueous/organic mixtures and the hydrogen production of $\mathrm{M}$ was 89.6 $\mu \mathrm{mol} / \mathrm{h}$ after reacted for 15 hours when $5 \%$ triethylamine was used as electron donor, $2.0 \mathrm{mM}$ fluorescein as photosensitizer and the catalyst content was $2.5 \mu \mathrm{M}$.

\section{Acknowledgments}

This work was supported by the National Natural Science Foundation of China (21106022), Science and Technology Planning Project of Guangdong Province, China (2013B010404045) and Educational Commission of Guangdong Province, China (Yq2013100).

\section{References}

[1] Mann M E, Bradley R S, Hughes M K. Global-scale temperature patterns and climate forcing over the past six centuries[J]. Nature, 1998, 392(6678): 779-787.

[2] Mann M E, Bradley R S, Hughes M K, et al. Global temperature patterns[J]. Science, 1998, 280(5372): 2027-2027.

[3] Christensen J H, Hewitson B, Busuioc A, et al. Regional climate projections[J]. Climate Change, 2007: The Physical Science Basis. Contribution of Working group I to the Fourth Assessment Report of the Intergovernmental Panel on Climate Change, University Press, Cambridge, Chapter 11, 2007: 847-940.

[4] Probst B, Kolano C, Hamm P, et al. An efficient homogeneous intermolecular rhenium-based photocatalytic system for the production of H2[J]. Inorganic Chemistry, 2009, 48(5): 1836-1843.

[5] Fihri A, Artero V, Pereira A, et al. Efficient H 2-producing photocatalytic systems based on cyclometalated iridium-and tricarbonylrhenium-diimine photosensitizers and cobaloxime catalysts[J]. Dalton Transactions, 2008 (41): 5567-5569. 
[6] Matt B, Moussa J, Chamoreau L M, et al. Elegant approach to the synthesis of a unique heteroleptic cyclometalated iridium(III)-polyoxometalate conjugate[J]. Organometallics, 2011, 31(1): 35-38.

[7] Du P, Knowles K, Eisenberg R. A homogeneous system for the photogeneration of hydrogen from water based on a platinum(II) terpyridyl acetylide chromophore and a molecular cobalt catalyst[J]. Journal of the American Chemical Society, 2008, 130(38): 12576-12577.

[8] Wang X, Goeb S, Ji Z, et al. Homogeneous photocatalytic hydrogen production using $\pi$-conjugated platinum(II) arylacetylide sensitizers[J]. Inorganic Chemistry, 2011, 50(3): 705-707.

[9] Lei P, Hedlund M, Lomoth R, et al. The role of colloid formation in the photoinduced H2 production with a RuII-PdII supramolecular complex: a study by GC, XPS, and TEM[J]. Journal of the American Chemical Society, 2008, 130(1): 26-27.

[10] Berben L A, Peters J C. Hydrogen evolution by cobalt tetraimine catalysts adsorbed on electrode surfaces[J]. Chemical Communications, 2010, 46(3): 398-400. 